\title{
Morpho- Functional Observations on Ontogenic development of the Renal excretory system in pre to post flexion stages larvae of Himalaya Snow trout Schizothorax plagiostomus (Heckel)
}

\author{
Rajesh Rayal ${ }^{1^{*}}$ \\ ${ }^{I}$ Department of Zoology, School of Basic and Applied Sciences, Shri Guru Ram Rai University, Dehradun, \\ Uttarakhand, India.
}

*Corresponding Email Id: drrajeshrayal@gmail.com

Received: 7.10.2021; Revised: 2.11.2021; Accepted: 7.11.2021

(O) Society for Himalayan Action Research and Development

\begin{abstract}
Schizothorax plagiostomus is one of the most important food fish inhabiting the snow-fed tributaries of the Himalayan region. Due to nutritional value, good growth rate, high economic prospects as well as the decline in the natural habitat its commercial production is desired. Keeping in view this fact, during the present investigation by following the artificial breeding and rearing experiments an attempt has been made to understand the morpho-functional development of the renal excretory system in pre to post-flexion stages larvae. The study reveals that all the essential basic structures of the renal excretory system (pronephros) were established before the initiation of external feeding. During the post-flexion stage when the yolk sac was almost reabsorbed and larvae exclusively depend on exogenous feeding the mesonephric tubules were forming and some of them become functional i.e. presence of glomerulus to maintain the internal environment as well as efficient removal of gradually increasing amount of nitrogenous wastes. The presence of lymphoid tissues was suggesting that cell-mediated immune responses develop progressively in the Himalayan snow trout $S$. plagiostomus larvae.
\end{abstract}

Keywords: Himalayan Snow trout, Schizothoraxplagiostomus, flexion stage, Kidney, renal system,Ontogeny, Organogenesis

\section{Introduction}

The renal excretory system is one of the most complex organs of the vertebrates and its function in regulating blood composition necessitates the coordinated activity of different cell types, which are meticulously arranged in the nephron and supporting tissue (Seldin and Giebisch, 1992; Drummond, 2000).In teleosts, differences in kidney form have been observed both externally and internally among various species. The head kidney is entirely made up of lymphoid tissue and lacks a nephron (Kapoor and Khanna, 2004). During the organogenesis of the larval kidney/renal system in teleosts, four phases are recognized: commitment of undifferentiated mesodermal cells to a nephrogenic fate; formation of the primordium, as well as the caudal growth and epithelialization of the pronephric duct; induction and formation of the nephron; and ingrowth of endothelial cells and the formation of the glomerular capillary tuft \& blood filter (Saxen, 1987; Drummond, 2000). During ontogeny, proper organogenesis and morpho-functional development of the organ systems are essential for the growth and survival of the larvae (Bahuguna and Rayal, 2006a,b,c; Rayal and Bahuguna 2006; Rayal et al., 2011; Rayal, 2020, 2021; Rayal et al., 2020,2021 ); the kidney is one of them as it is associated with the excretion of waste, osmoregulation, acid-base balance, secretion of hormones, reabsorption of metabolites, immune response, etc. In light of this, an attempt has been made to comprehend the mechanism of organogenesis of the kidney/renal excretory system during ontogeny in Hillstream Himalayan snow trout $S$. plagiostomus pre to post-flexion stages larvae.

\section{Material and Methods}

To obtain the desired pre to post-flexion larvae, artificial fertilization was carried out on the bank of the Alaknanda River in Srinagar Garhwal, Uttarakhand, India, during the breeding season (September-October). Fertilized eggs were transferred to the laboratory and placed in incubation and hatching trays, glass jar hatcheries, and hatching tubs with sufficient aeration, suitable temperature (17-200C), and consistent water supply. Some of the fertilized eggs of the same 
batch were also placed in incubation \& hatching trays on a small stream of river to ensure proper development in natural habitat. The behavior and developmental changes among the larvae at both the laboratory and natural sites were monitored up to the postflexion stage. For the subsequent morphofunctional and histological analysis, 5-10 larvae were fixed in different fixatives, viz. aqueous bouins, alcoholic bouins, $4 \%$ formalin, calcium formol, and $70 \%$ alcohol, etc. from hatching to post-flexion stages at 4-8 hrs intervals. After completing fixation (18-24 hours) in bouins, samples were rinsed and then dehydrated in an increasing series of ethanol for embedding. Following the embedding in paraffin wax (E. Merck, 54-560C melting point paraffin wax), transverse and longitudinal sections of 5-6 $\mu \mathrm{m}$ were obtained using an Erma Rotary Microtome. After dewaxing, the serially ordered stained sections were mounted in DPX, and photomicrographs were made using an Olympus-photomicroscopic system.

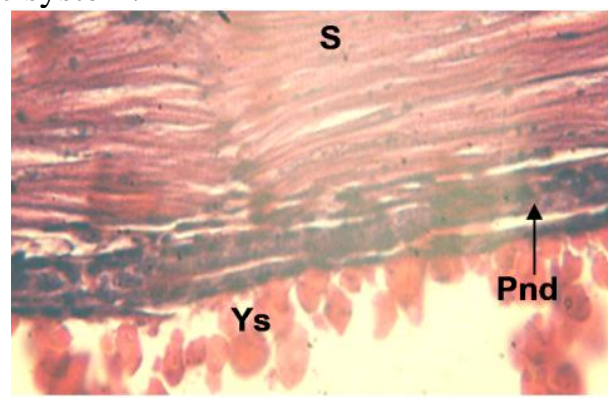

\section{Results}

The microscopic examination of the serially arranged sections (L.S. \& T.S.) of hatchlings shows that the renal excretory system and other visceral organs were not differentiated at hatching. It proceeds gradually in an anteriorposterior direction after eight hours of hatching.

The pronephric duct differentiates from the renal primordial cells or primordia by the second dph. Between the yolk sac and the notochord, it runs anterior-caudally (Figure-1). Pronephric nephrons and tubules form shortly after the pronephric duct and were connecting the anterior-most tips of pronephric ducts. On $3-4^{\text {th }} \mathrm{dph}$ convolution in the anterior portion of pronephric tubules, and some of the erythroid and lymphoid tissue were observed associated with this region (Figure-2). At the same time, the caudal portion of the pronephric duct (near cloaca) starts to become broader than the comparison of other parts.

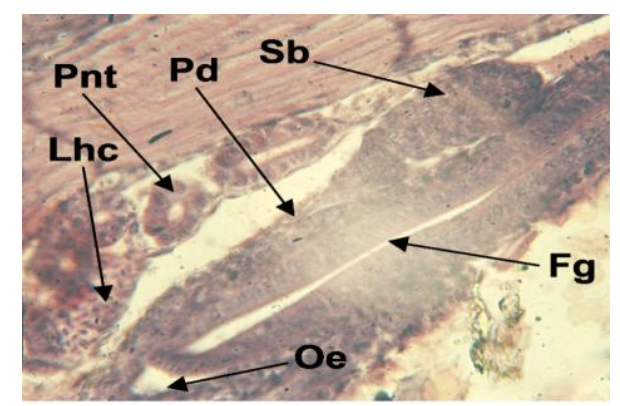

Figure-1. L.S. of $2^{\text {nd }} \mathrm{dph}$ larvae showing pronephric duct running anterior-caudally, between yolk sac and notochord (H.E. 280X).

Figure-2. L.S. of $3^{\text {rd }}$ dph larvae showing differentiation of swim bladder anlage as a cluster of mesenchymal cell from the dorsal wall of the esophagus, pronephric tubule with rudimentary hemopoietic and lymphatic tissues, yolk sac, etc (H.E. 280X).
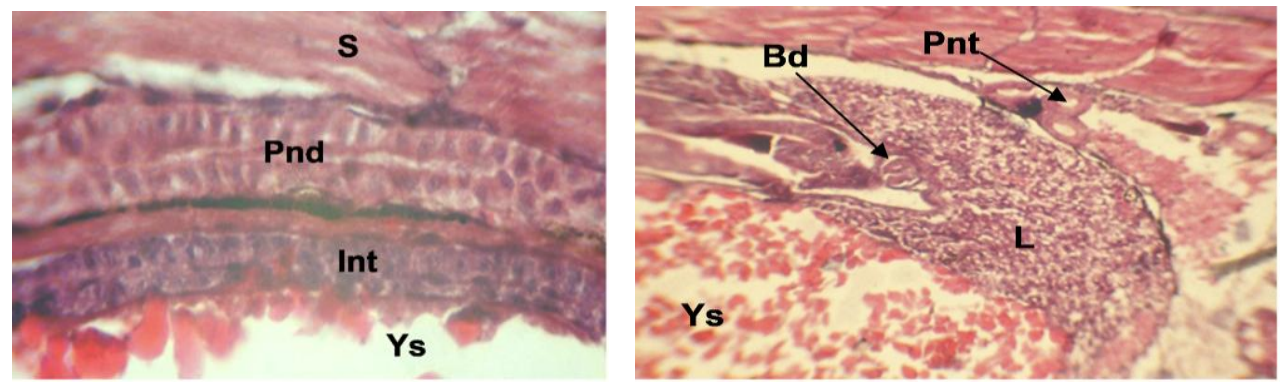

Figure-3. L.S. of $7^{\text {th }}$ dph larvae showing pronephric duct at the trunk kidney, midgut portion, and yolk sac, etc (H.E. 100X) Figure-4. L.S. of $9^{\text {th }} \mathrm{dph}$ larvae showing the opening of the bile duct in the fore gut, liver cells around the bile duct, and foregut, Kidney, etc. (H.E. 100X). 

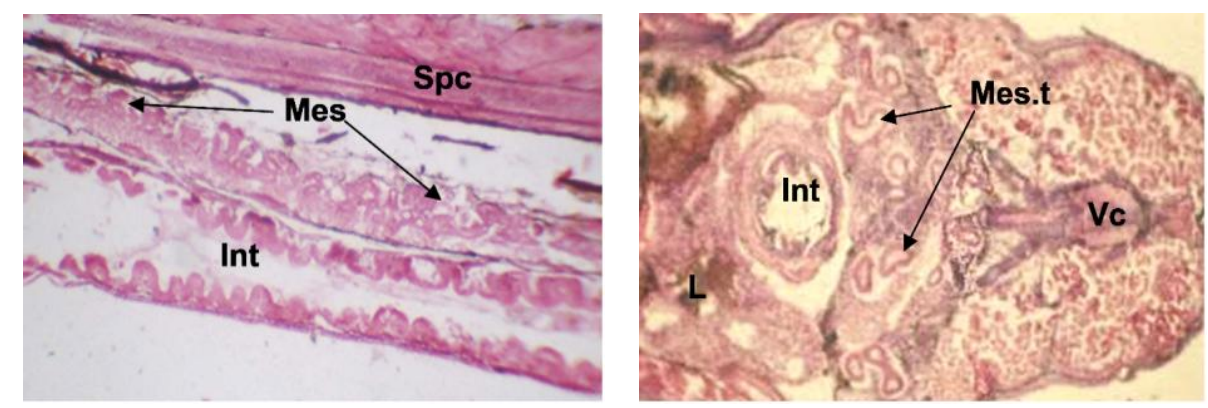

Figure-5. L.S. of $12^{\text {th }}$ dph larvae showing the development of the segmented tubules of mesonephros (H.E. 100X).

Figure-6. L.S. of $14^{\text {th }}$ dph larvae showing formation and coiling of mesonephric tubules in trunk kidney. (H.E. 100X).
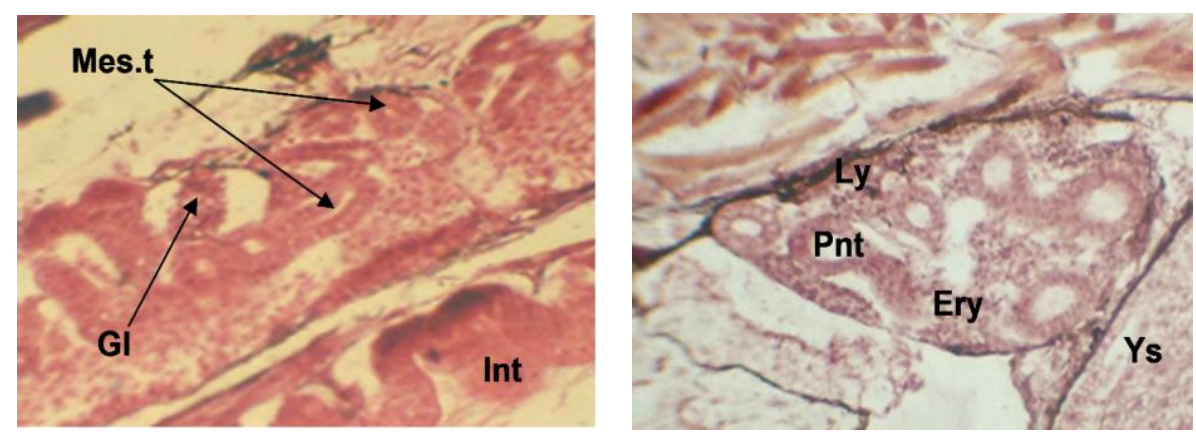

Figure-7. L.S. of $15^{\text {th }}$ dph larvae showing glomerulus, proximal and distal tubules of mesonephros (Mes.t), etc. (H.E. 100X). Figure-8. L.S. of $15^{\text {th }}$ dph larvae showing head kidney: pronephric tubule consists of large columnar epithelial cells, erythroid and lymphatic tissue. (H.E. 100X).

\begin{abstract}
Abbreviations
$\mathrm{Bd}=$ bile duct, Ery= erythroid tissue, $\mathrm{Fg}=$ fore gut, $\mathrm{Gl}=$ glomerulus, Int= intestine, $\mathrm{L}=$ eye lens, $\mathrm{Lhc}=$ lymphatic and hemopoietic cells, $\mathrm{Ly}=$ lymphatic tissue, Mes= mesonephros,Mes.t= mesonephric tubule, $\mathrm{Oe}=$ oesophagus, $\mathrm{Pd}=$ pneumatic duct, $\mathrm{Pnd}=$ pronephric duct, $\mathrm{Pnt}=$ pronephric tubules, $\mathrm{S}=$ somites, $\mathrm{Sb}=$ swim bladder, $\mathrm{Spc}=$ spinal cord, $\mathrm{Vc}=$ vertebral column, $\mathrm{Ys}=$ yolk sac
\end{abstract}

Pronephric tubules were more convoluted in 6$7^{\text {th }} \mathrm{dph}$ larvae. Until the one-half of flexion stage $\left(9^{\text {th }} \mathrm{dph}\right)$ kidney remains completely pronephric; no evidence of mesonephros at the trunk and caudal region (Figure-3). Convolutions of nephric tubules were observed in the anterior portion of the kidney. Erythroid and lymphoid tissues associated with this portion were increasing in size (910th dph; Figure-4). By $10-11^{\text {th }}$ dph urinary duct open into a small sac (slightly broad portion) which was closely associated with the posterior digestive tract. The segmented tubules of mesonephros were forming during the commencement of exogenous feeding or post flexion stage $\left(12-13^{\text {th }} \mathrm{dph}\right.$;Figure-5). During the 14-15th dph hemopoietic tissues were developing around the pronephric tubules (Figure-8). The coiling of the mesonephric tubules was becoming more extensive (Figure-
6). Some tubules were found with large blastlike cells (columnar epithelial cells) between the nephric tubules (Figure-7). As development continued the blast-like cells increased in number, and become smaller and darker in appearance. The development of mesonephric kidney was continued; distinct increase in hematopoietic tissue and a variety of cell types were evident there during the 20$22^{\text {nd }} \mathrm{dph}$.

\section{Discussion}

The general pattern of renal excretory system development in $S$. plagiostomus is almost comparable to that described in other fish, although the timing differs. The absence of functional mesonephric kidneys during the early stages (especially during pre-flexion and flexion stages) of larval development in most fishes, including $S$. plagiostomus, is usually the major variation in their renal system 
between larvae and adults. The pronephros, also known as the pronephric kidney in teleosts, is made up of only two nephrons with glomeruli fused at the midline, pronephric tubules connected directly to the glomeruli via a neck segment, and paired bilateral pronephric ducts that transport the altered blood filtrate outside the animal (Tytler, 1988; Drummond et.al., 1998). According to Vize et. al. (1997), Drummond et.al. (1998) all functional pronephroi receive their blood supply from the dorsal aorta. During the current investigation, similar observations were obtained in S. plagiostomus larvae.

Pronephric primordium appears as a mass of intermediate mesoderm lying beneath the anterior somites during early somitogenesis in amphibians and teleost fishes, and future pronephros is derived from this cluster of cells (Kimmel et.al, 1995; Vize et. al., 1997). By the $2^{\text {nd }} \mathrm{dph}$ in $S$. plagiostomus, the renal anlage was visible under the optical microscope, progressing from anterior to caudal. The pronephric duct develops before the pronephric nephrons and tubule from kidney primordia.Tytler (1988), Tytler et al. (1996), Drummond et al. (1998), and Drummond (2000) observed similar phenomena in other fishes.

From three to seven dph larvae of $S$. plagiostomus, the anterior side of the pronephric tubules becomes more convoluted, some erythroid and lymphoid tissue is also associated with this region, and the caudal portion of the pronephric duct becomes slightly wider than the other portions. Some researchers have noticed similar phenomena in other fishes at various phases of their early growth. While in Oreochromis niloticus pronephric tubules appears at 46-48 hrs of fertilization and its convolution, as well as the development of erythropoietic and lymphoid tissue, occurs before hatching i.e. $100 \mathrm{hrs}$ after fertilization (Morrison et.al., 2001 ). Kato et al. (2004) reported a well-established kidney with erythropoietic and lymphoid components in Epinephelusbruneusat hatching in kelp grouper.

The pronephros in several fish genera, such as Fierasfer, Zoarces, and Lepadogaster, remains functioning throughout their lives (Kerr, 1919; Hickman and Trump, 1969; Lagler et al., 1977). As the mesonephros develops, most vertebrates' pronephros degenerate, and the anteriormost region becomes hemopoietic; this is referred to as the head kidney (Drummond, 2000; Reimschuessel, 2001).As with development, this process progressed anterior to the posterior end. In the present study, such type of phenomenon has been observed by 1011 th dph. The mesonephros is the functional kidney of adult teleosts, and it is also functional in the mammalian embryo at various stages of development (Davies and Routh, 1957; Leeson and Baxter, 1957; Martino and Zamboni, 1966; and Tiedemann, 1976).

In more posterior segments, the mesonephros arises from the nephrotome. The tubular outgrowths, Bowman's capsule and glomerulus, are formed like that of the pronephros (Fraser, 1950; Goodrich, 1958).Renal vesicle is formed by the formation of a cavity in the center of the cluster of nephrotomic cells located near the pronephric duct. Initially, it becomes C-shaped but later on changed into $\mathrm{S}$-shape. The glomerulus and peritoneal funnel are formed respectively by the invagination and evagination of the medial end of the S-shaped vesicle. The remaining portion of the $S$-shaped vesicle differentiates into the primary tubule which fuses with the pronephric excretory duct by the outgrowth and ultimately becomes mesonephric duct. Secondary and tertiary tubules differentiates from the nephrogenic cluster of the nephrotome and are finally fused with the primary duct. The tertiary tubule opens into the secondary tubules. In due course of time, all the tubules elongate, become coiled, and interwine forming the mesonephros (Reimschuessel, 2001). A similar pattern supports the developmental phases in S. plagiostomuslarvae during pre to post-flexion stages.

The current investigation on the development of $S$. plagiostomusreveals that mesonephros differentiation continued during the postflexion stage. Drummond (2000) made similar observations about a variety of other teleosts.

After the fourteenth to fifteenth dph, $S$. plagiostomus larvae showed a gradual rise in the volume of erythropoietic and lymphatic tissue in the kidney and other lymphatic organs, indicating the development of cellmediated immune responses. The thymus and 
kidney are the two most significant primary lymphoid organs. The kidney is the equivalent of adult mammals' bone marrow as a source of B lymphocytes (Zapata, 1979; Zapata et.a., 1996; Zapata and Amemlya, 2000), suggesting that cell-mediated immune responses develop progressively in Himalayan snow trout $S$. plagiostomus larvae.

\section{Acknowledgment}

The author sincerely acknowledges Prof. S.N. Bahuguna, Department of Zoology and Biotechnology, Srinagar Campus, H.N.B. Garhwal University (Central University) Srinagar Garhwal, for constant supervision and encouragement.

\section{References}

Bahuguna, S.N. and Rayal, R. (2006a). Posthatching developmental study of the hepatic and pancreatic structures in the laboratory-reared larvae of Himalayan snow trout Schizothoraxplagiostomus (Heckel). Flora and Fauna. 12 (1): 4550.

Bahuguna, S.N and Rayal, R. (2006b). Histomorphological study of the optic tissue in the larvae of Himalayan Snow Trout Schizothoraxplagiostomus (Heckel). Aquacult. 7(2): 153-158.

Bahuguna, S.N and Rayal, R. (2006c). Morpho-histological study of the brain in Schizothoraxplagiostomus (Heckel) larvae with special reference to its feeding habit. Him. J. Envt. Zool. 20 (2): 231-235.

Davies, J. and Routh, J.I. (1957). Comparison of the foetal fluids of the rabbit. $J$. Embryol. Exp. Morph. 5: 32-39.

Drummond, I.A. (2000). The zebrafish pronephros: a genetic system for studies of kidney development. PediatrNephrol. 14: 428-435.

Drummond, I.A., Majumdar, A., Hentschel, H., Elger, M., Solnica- Krezel, L., Schier, A.F., Neuhauss, S.C., Stemple, D.L., Zwartkruis, F., Rangini, Z., Driever, W. and Fishman, M.C. (1998). Early development of the zebrafish pronephros and analysis of mutations affecting pronephric function. Development. 125: 4655-4667.
Fraser, E.A. (1950). The development of the vertebrate excretory system. Biol. Rev. 25: 159-187.

Goodrich, F.S. (1958). Studies on the structure and development of vertebrates. New York Press: Dover. 657-719.

Hickman, C.P. and Trump, B.F. (1969). The kidney. In: Hoar and Randall (eds). Fish Physiology, Academic Press, New York. 1: 91-239.

Kapoor, B.G. and Khanna, B. (2004). Ichthyology handbook. Narosa Publishing house, New Delhi.

Kato, K., Ishimaru, K., Sawada, Y., Mutsuro, J., Miyashita, S., Murat, O. and Kumai, H. (2004). Ontogeny of digestive and immune system organs of larval and juvenile kelp grouper Epinephelusbruneus reared in the laboratory. Fisheries Science. 70: 10611069.

Kimmel, C.B., Ballard, W.W., Kimmel, S.R., Ullmann, B., and Schilling, T.F. (1995) Stages of embryonic development of the zebrafish. Dev. Dyn. 203: 253-310.

Lagler. K.F., Bardach, J.F., Miller, R.R. and Passimo, M. (1977). Ichthyology. New York: John Wiley \& Sons. 91-267.

Meeson, T.S. and Baxter J.S. (1957). The correlation of structure and function in the mesonephros and metanephros of the rabbit. J. Anat. (Lond). 91: 383-390.

Martino, C. and Zamboni L. (1966). A morphologic study of the mesonephros of the human embryo. Ultrastructure Res. 16: 399-427.

Morrison, Carol M., Tsutomu, M., James, R. and Wright, Jr. (2001). Histological Study of the Development of the Embryo and Early Larva of Oreochromis niloticus (Pisces: Cichlidae).Journal of Morphology 247:172-195

Rayal, R. (2020). Morpho-functional and developmental study of swim bladder in pre to post-flexion stages larvae of Himalayan snow trout Schizothoraxplagiostomus(Heckel) reared in artificial and natural conditions. $J$. Mountain Res. 15: 141-149. DOI: https://doi.org/10.51220/jmr.v15i1.17

Rayal, R. (2021). Ontogenic development of gills in pre to post-flexion stages larvae of Himalayan Snow Trout 
Schizothoraxplagiostomus (Heckel) J. Mountain Res.16(1): 119-125. DOI: https://doi.org/10.51220/jmr.v16i1.11

Rayal, R. and Bahuguna, S.N. (2006): Comparative pre and post-hatching morphological developmental study of Schizothoraxplagiostomus (Heckel) in relation to different environmental (natural and confined) conditions. $J$. Natural Resources \& Development, 1(2): 110-118

Rayal, R., Saher, A., Bahuguna, P. and Negi, S. (2020). Study on breeding capacity of snow trout Schizothoraxrichardsonii (Gray) from river Yamuna, Uttarakhand, India. The Scientific Temper. 11:1-2.Doc ID:

https://connectjournals.com/03960.2020.1 $\underline{1.87}$

Rayal, R., Saher, A., Madan, S., Bharti, S. and Rana, N. (2021). Snow trout, Schizothoraxrichardsonii (Gray), from the river Yamuna, Uttarakhand, India: a study on the length-weight relationship and relative condition factor.Uttar Pradesh Journal of Zoology,42(18): 105112.

Rayal, R., Thapliyal, M. and Bahuguna, S.N. (2011). Fertilization and larval development of the Himalayan snow trout Schizothoraxplagiostomus (Heckel). Himalayan Aquatic Biodiversity conservation and Tools in Biotechnology. Transmedia Publication, Srinagar Garhwal, Uttarakhand, India. 156-166

Reimschuessel, R. (2001). A fish model of renal regeneration and development. ILAR Journal. 42(4): 285-91.

Saxen, L. (1987). Organogenesis of the kidney. Cambridge University Press, Cambridge.

Seldin, D.W. and Giebisch, G.H. (1992). The kidney: physiology and pathophysiology, 2nd edn. Raven, New York.

Tiedemann, K. (1976). The mesonephros of cat and sheep. Adv. Anat. Embryol. Cell Biol. 52: 3-119.

Tytler, P. (1988). Morphology of the pronephros of the juvenile brown trout, Salmo trutta. J. Morphol. 195:18920423.

Tytler, P., Ireland, J., Fitches, E. (1996). A study of the structure and function of the pronephros in the larvae of the turbot (Scophthalmus maximus) and the herring (Clupea harengus). Mar. Fresh Behav. Physiol. 28: 3-18.

Vize, P.D., Seufert, D.W., Carroll, T.J. and Wallingford, J.B. (1997). Model systems for the study of kidney development: use of the pronephros in the analysis of organ induction and patterning. Dev. Biol. 188: 189-204. 